\title{
The impact of obstructive sleep apnoea on the aorta
}

\author{
Thomas Gaisl ${ }^{1}$, Daniel J. Bratton ${ }^{1}$ and Malcolm Kohler ${ }^{1,2,3}$
}

\section{Affiliations:}

${ }^{1}$ Dept of Pulmonology, University Hospital Zurich, Zurich, Switzerland.

${ }^{2}$ Centre for Integrative Human Physiology, University of Zurich, Zurich, Switzerland.

${ }^{3}$ Centre for Interdisciplinary Sleep Research, University of Zurich, Zurich, Switzerland.

\section{Correspondence:}

Malcolm Kohler, Dept of Pulmonology, University Hospital Zurich, Rämistrasse 100, 8091 Zurich, Switzerland.

E-mail: Malcolm.KohlerQusz.ch

ABSTRACT Obstructive sleep apnoea (OSA) has been shown to be a causal factor in the pathogenesis of vascular dysfunction and hypertension, conditions which can promote dilation and subsequent aortic dissection and rupture. The objective of this review is to summarise the current literature on the possible association between OSA and aortic disease and delineate the underlying mechanisms.

Relevant studies were found by searching for terms including "obstructive sleep apnoea" in combination with "aortic aneurysm, dissection, and dilation" in the MEDLINE and EMBASE databases.

Observational studies consistently reported that OSA is highly prevalent among patients with aortic aneurysms and aortic dissections. Patients with co-occurring OSA and Marfan's syndrome as well as patients at the more severe end of the spectrum of OSA seem to be especially vulnerable to aortic disease.

Several mechanisms are discussed concerning the link between OSA and aortic disease: nocturnal negative intrathoracic pressure surges leading to mechanical stretching of the aorta and ultimately aortic distension; arousal-induced reflex sympathetic activation with subsequent hypertension; and intermittent hypoxia associated with autonomic nervous system activation and consequently increased oxidative stress. Further well controlled studies are needed in order to define the exact role of OSA as a risk factor for aortic disease.

@ERSpublications

Several studies have shown an association between obstructive sleep apnoea and aortic aneurysms/dissections http://ow.ly/Nh9jc

This article has supplementary material available from erj.ersjournals.com

Received: Feb 202015 | Accepted after revision: April 292015 | First published online: June 252015

Support statement: This review was funded by the Clinical Research Priority Program (CRPP) Sleep and Health from the University of Zurich. Funding information for this article has been deposited with FundRef.

Conflict of interest: None declared.

Copyright OERS 2015 


\section{Introduction}

Obstructive sleep apnoea (OSA) is highly prevalent, with at least $20 \%$ of males and $10 \%$ of females in Western countries affected by asymptomatic OSA [1-4]. Pathophysiologically, the disease is characterised by repetitive partial or complete obstruction of the pharynx during sleep. Despite increasing breathing efforts the upper airway collapse results in episodes of obstructive hypopnoeas or apnoeas affecting the sleep architecture and the whole body via instant and long-term mechanisms.

Determining the potential contribution of OSA to cardiovascular risk is challenging. A large proportion of research on OSA is dedicated to cardiovascular consequences, where a causal relationship between OSA, major adverse cardiovascular events [5-7], heart failure [5] and mortality [8] has been suggested yet not definitely established. By contrast, OSA has been confirmed to be a causal factor in the pathogenesis of vascular dysfunction and hypertension $[9,10]$. Cohort studies including the Sleep Heart Health Study have consistently demonstrated that over $50 \%$ of individuals with OSA have hypertension $[1,11,12]$. Sustained and effective treatment of OSA with continuous positive airway pressure (CPAP) has been reported to improve daytime symptoms and quality of life $[13,14]$ and to reduce blood pressure [15], one of the major risk factors for aortic dilation [16].

An aortic aneurysm is defined as a permanent, localised dilation of the aorta that includes all three layers of the vessel [17]. The prevalence of thoracic aortic aneurysms (TAA) and abdominal aortic aneurysms (AAA) is $0.16-0.34 \%[18,19]$ and $1.2 \%$ [20], respectively, with a markedly higher prevalence in men aged $>60$ years. Currently, aortic aneurysms in general represent the 18th leading cause of death in the USA [21]. Pathogenesis and treatment differ slightly for aortic aneurysms depending on the exact location [22]; however, about $25 \%$ of patients with TAA also have AAA, suggesting similar risk factors for both diseases [23]. Aortic aneurysms represent a group of disorders resulting from connective tissue diseases, inflammatory components [24], hypertension and atherosclerosis [23, 25] and are associated with high rates of morbidity and mortality due to dissection and/or rupture [23, 26]. Besides the treatment of the underlying risk factors, elective repair of large-diameter aneurysms and aneurysms with a high expansion rate is recommended. Because aneurysms are usually asymptomatic, a timely detection and knowledge of the underlying risk factors is crucial.

The potential impact of OSA on cardiovascular burden and aortic disease is likely to be related in large part to its association with elevated blood pressure. Ambulatory blood pressure is particularly elevated during sleep compared with the awake period and OSA patients often present a non-dipping pattern (diminished nocturnal blood pressure fall) or riser pattern (sleep blood pressure higher than awake blood pressure) of nocturnal blood pressure [27]. Regardless of how blood pressure is measured, there is a significant association between OSA severity and elevated blood pressure [28]. It is generally accepted that hypertension can cause thoracic aortic dilation [29] and is the main risk factor for aortic dissection (AD) [26], although the exact pathophysiology remains unclear. Chronic hypertension and its vascular consequences are major yet fractional risk factors, since it is not rare for aortic disease to also develop in adequately treated patients $[22,30]$. It is therefore thought that OSA may act through a number of other pathomechanisms to elicit vascular damage. However, because of the association between common risk factors (e.g. age, male sex, hypertension, etc.) and both OSA [1,31-33] and aortic disease [23, 25, 30], it is difficult to establish the true effect of OSA.

The purpose of this review is to summarise the clinical evidence and synthesise the pathophysiological mechanisms between OSA and aortic disease, namely: 1) aortic dilation, 2) aortic aneurysms (TAA and AAA), and 3) AD. The aim is to provide clinicians with a clear picture of the current literature on this topic, discuss potential implications for clinical practice and highlight areas of future research for this highly prevalent sleep disorder.

\section{Methods \\ Inclusion criteria}

Studies were eligible if they covered (at least in one aspect) the topic of the impact of OSA on aortic disease (aortic dilation, AD, TAA, AAA) or vice versa. Studies in humans and in English published until January 1, 2015 were considered for this review. We did not include case reports, reviews, conference abstracts and studies investigating aortic stiffness. No other restrictions were used.

\section{Search strategy}

We performed electronic database searches in MEDLINE (Ovid version, New York, NY, USA) and EMBASE (DataStar Version, Cary, NC, USA). The search was conducted using the following medical subject heading (MeSH) terms: "obstructive sleep apnea" in combination with "aortic dila(ta)tion", "aortic aneurysm" and "aortic dissection", including alternative MeSH entry terms. The bibliographies of all 
articles that fulfilled the inclusion criteria were screened to identify other articles that fulfilled the inclusion criteria.

\section{Results}

Searches of electronic databases identified 23 eligible studies with a total of 2800 patients. Figure 1 shows the flow diagram for identification of relevant studies. Complete search results are available in the online supplementary material (table S1). In this results section, the evidence from clinical studies on the impact of OSA on aortic disease will be reviewed, followed by a discussion of the potential underlying mechanisms.

\section{Evidence from clinical studies on the impact of OSA on aortic disease}

\section{Marfan's syndrome}

Research on the impact of OSA on aortic disease is based upon early studies in patients with Marfan's syndrome. Marfan's syndrome is a genetic multisystem connective tissue disorder associated with craniofacial abnormalities and increased upper airway collapsibility, both of which are linked to OSA [3437]. Aortic dilation and associated $\mathrm{AD}$ and rupture are the main cause of morbidity and mortality in patients with Marfan's syndrome, cutting life expectancy by about one third compared with the general population [38, 39]. In 1993, it was first suspected by Cistulli and Sullivan [40] that OSA might have deleterious effects on aortic dilation and subsequent rupture. They attributed, at least in part, the reduced life expectancy due to aortic complications to the high OSA prevalence among patients with Marfan's syndrome [40]. Later, a considerably high OSA prevalence in patients with Marfan's syndrome was confirmed and a moderate correlation between the apnoea-hypopnoea index (AHI) and maximal aortic root diameter was found $(\mathrm{r}=0.5, \mathrm{p}<0.001,95 \%$ CI $0.2-0.69)$ [41, 42]. A follow-up study in 44 patients with

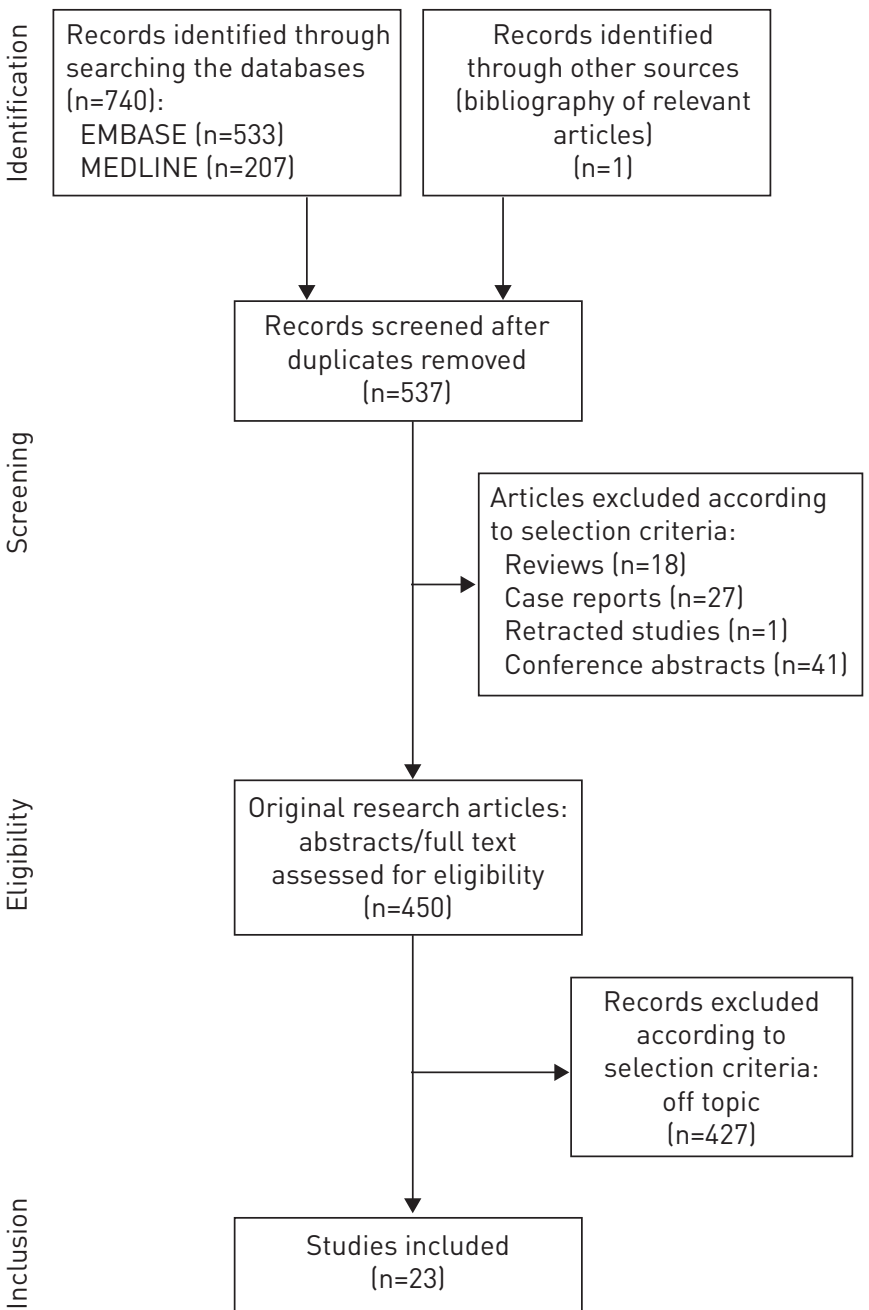

FIGURE 1 Flow diagram for identification of relevant studies. 
Marfan's syndrome was then performed to further explore the longitudinal association between OSA and aortic disease [43]. After a median follow-up time of 29 months, only subjects with OSA developed an aortic event, defined as an operation because of progressive aortic dilation or death because of aortic rupture. The AHI was associated with aortic events in univariable analysis (hazard ratio 1.09, 95\% CI 1.01-1.18), but not when other covariates (age, sex, systolic blood pressure, antihypertensive medication, baseline aortic diameter) were accounted for, possibly due to a lack of statistical power [43]. Up to now, this represents the only longitudinal study where the impact of OSA on aortic disease (by means of events rather than disease parameters) has been investigated.

\section{General population}

Studies in the general population show a somewhat mixed body of evidence (table 1). Most of the studies investigated the association between OSA and the aortic root diameter [44-52]. Six cross-sectional studies investigating patients referred for a sleep evaluation reported a positive association between the aortic root diameter and parameters of OSA severity (either AHI or oxygen desaturation index (ODI)) [45, 48-52]. Notably, one study found an association with AHI in rapid eye movement sleep only where the severity of OSA becomes greater, partly due to a decreased respiratory muscle tone [52]. Another study reported this association in patients with hypertrophic cardiomyopathy [48].

By contrast, two prospective [44, 47] and one retrospective study [46] did not establish the aforementioned relationship. TANRIVERDi et al. [44] reported no difference in aortic diameters (systolic/diastolic) in a matched OSA case-control study. This finding is in agreement with another retrospective study that assessed aortic diameter in 76 OSA patients and found age and sex to be the only determinants for aortic root dilation [46]. However, $84 \%$ of these patients were treated with CPAP, which is likely to dilute the association between AHI and aortic diameter [46]. Another study investigated patients with acute myocardial infarction for an association between OSA and aortic diameter [47]. Stepwise multivariable regression revealed that body mass index (BMI), age and hypertension, but not AHI, showed an independent relationship with thoracic aortic diameter [47]. A somewhat different picture emerged, however, if OSA patients were subdivided into AHI groups. Compared with controls, only severe OSA patients (AHI $>30$ events $\left.\cdot h^{-1}\right)$ had a larger aortic diameter $(p=0.048)$ [47]. One could therefore hypothesise that the adverse impact of OSA on the aorta only deploys above a certain AHI threshold, which is possibly higher than the common diagnostic threshold of AHI $\geqslant 5$ events $\cdot \mathrm{h}^{-1}$.

Another study retrospectively assessed computed tomography-derived abdominal aortic diameters at three anatomic locations in 427 subjects. After adjusting for major AAA risk factors, OSA (defined as AHI $\geqslant 10$ events. $\mathrm{h}^{-1}$ ) was an independent risk factor for distal abdominal aortic dilation in men [53].

\section{Prevalence of OSA among aortic disease patients}

In 2003, SAMPOL et al. [54] reported a higher AHI in 19 patients with AD compared with 19 controls matched for age, sex and BMI $(\mathrm{p}=0.032)$. Although the OSA prevalence (defined by AHI $>5$ events $\cdot \mathrm{h}^{-1}$ ) did not differ between $\mathrm{AD}$ patients and the matched control group (68\% in each group), their findings are largely attributable to the high number $(n=7)$ of severe OSA cases in the AD group versus one case in the control group $(\mathrm{p}=0.042)$. In other words, $\mathrm{AD}$ patients presented a higher burden of nocturnal apnoeic events and severe OSA (defined by AHI $>30$ events. $h^{-1}$ ). Similar case-control studies also reported higher percentages of moderate to severe $\mathrm{ODI}$ in $\mathrm{AD}$ patients versus controls $[55,56]$ and two other studies concluded that $\mathrm{AD}$ is associated with OSA $[57,58]$. These findings raise the question of whether a high $\mathrm{AHI} /$ severe OSA is also more prevalent in other forms of aortic disease.

An international multicentre study found that $\sim 40 \%$ of patients aged $18-75$ years in an AAA surveillance register presented with an AHI $>10$ events $\cdot h^{-1}$ [59]. Cross-sectional data indicated no association of aortic diameter with AHI [59]. In order to investigate a possible association between OSA/AHI and rate of AAA expansion, MASON et al. [59] assessed patients with AAA during a median follow-up interval of 18 months. From the total cohort $(n=127)$, patients with severe forms of OSA (ODI $>30$ events $\left.\cdot h^{-1}\right)$ had a significantly faster median yearly AAA expansion rate than patients with ODI $<5$ events $\cdot \mathrm{h}^{-1}(\mathrm{p}<0.05)$, independent of cardiovascular risk markers [59]. Other studies using indirect measures of OSA (Berlin Questionnaire) reported that about 60\% of AAA patients are likely to have OSA [60]. Finally, SARUHARA et al. [61] conducted a case-control study where TAA, AAA and AD patients were found to have a higher incidence of moderate to severe OSA (AHI $>15$ events $\cdot h^{-1}$ ) than controls. Table 2 summarises studies on the prevalence of OSA among aortic disease patients.

\section{Physiological studies in healthy volunteers}

Three studies have investigated the pathophysiological effects of OSA using breathing manoeuvres that simulate OSA features in healthy volunteers (table 3) [62-64]. The Müller manoeuvre (simulated 
TABLE 1 Current evidence from clinical studies on the impact of obstructive sleep apnoea (OSA) on aortic disease

$\begin{array}{lllll}\text { First author Year Design } & \text { Population } & \text { Subjects } \mathbf{n} & \text { Outcome measures }\end{array}$

[ref.]

$\begin{array}{ccccc}\text { TANRIVERDI [44] } 2006 & \text { Case-control } & \text { Sleep laboratory } & \begin{array}{c}\text { 40, plus } 24 \\ \text { controls }\end{array} & \begin{array}{c}\text { IMT, FMD, aortic } \\ \text { stiffness }\end{array}\end{array}$

SeRIzaWa [45] 2008 Cross-sectional Sleep laboratory

150

76

$\begin{array}{lcccc}\text { KohleR [41] } & 2009 & \text { Case-control } & \begin{array}{c}\text { Marfan's } \\ \text { syndrome }\end{array} & \begin{array}{c}\text { 61, plus 26 } \\ \text { controls }\end{array} \\ \text { LeE [47] } & 2010 & \text { Cross-sectional } & \begin{array}{c}\text { Acute } \\ \text { myocardial } \\ \text { infarction }\end{array} & 94 \\ \text { PedRosa [48] } & 2010 & \text { Case-control } & \text { HCM } & \text { 32, plus 48 } \\ \text { controls }\end{array}$

CICEK [49] 2011 Cross-sectional Sleep laboratory

Achour [50] 2011 Cross-sectional $\begin{gathered}\text { General } \\ \text { population }\end{gathered}$

Baguet [51] 2011 Cross-sectional Sleep laboratory

Marfan's

KoHLER [43]

2013

Prospective
cohort

syndrome

Chen [52]

Case-control

Sleep laboratory

65 , plus 14 controls

427
156

90

303
AHI, aortic diameter

AHI, aortic diameter, aortic stiffness

OSA prevalence, correlation of $\mathrm{AHI}$ and aortic diameter

$\mathrm{AHI}$, aortic root

Left atrial diameter, aortic diameter
AHI, aortic root size, left ventricle dysfunction

Mean nocturnal oxygen saturation, aortic root

Aortic root, nocturnal hypoxia, diastolic BP, AHI, BRS

Aortic events

ardiac function, aortic root

Abdominal aortic diameter at three anatomic landmarks
OSA is associated with higher values of aortic stiffness and IMT but lower distensibility and FMD lincluding data on aortic diameter)

$\mathrm{AHI}$ is independently associated with greater thoracic aortic diameter

The prevalence of aortic root dilation in OSA is 3.9\%; no association between OSA and aortic parameters

OSA is highly prevalent in Marfan's syndrome; $\mathrm{AHI}$ correlates with aortic diameter

BMI, age and hypertension, but not $\mathrm{AHI}$, determine thoracic aortic size

OSA is highly prevalent in HCM patients and is associated with left atrial and aortic enlargement

Severity of OSA (AHI) correlates with aortic root diameter

Nocturnal hypoxaemia is associated with aortic root size in the elderly

Nocturnal hypoxaemia, decreased BRS and increased diastolic BP are associated with greater aortic root size in OSA

Aortic event-free survival may be shorter in patients with Marfan's syndrome and OSA compared with patients without OSA

Patients with moderate to severe OSA tend to have cardiac dysfunction lincluding data on aortic diameter)

OSA is independently associated with dilation of the distal abdominal aorta in men

IMT: carotid intima-media thickness; FMD: flow-mediated dilation; AHI: apnoea-hypopnoea index; BMI: body mass index; HCM: hypertrophic cardiomyopathy; BRS: baroreflex sensitivity; BP: blood pressure.

obstructive apnoea) has proven to be an elegant way to partially simulate acute effects of OSA without the confounding factors of profound hypoxaemia, arousals from sleep and comorbidities often present in patients with OSA [65]. In humans, the Müller manoeuvre and simulated obstructive hypopnoea (inspiration through threshold load) induced considerable changes in blood pressure and simulated obstructive hypopnoea has been shown to be associated with an increase in proximal aortic diameter and aortic area $[62,64]$. The underlying forces of this increase were quantified in a second study, which concluded that simulated obstructive apnoea/hypopnoea increased aortic wall dilatory pressures [63]. 
TABLE 2 Prevalence of obstructive sleep apnoea (OSA) among aortic disease patients

\begin{tabular}{|c|c|c|c|c|c|c|c|}
\hline $\begin{array}{l}\text { First author } \\
\text { [ref.] }\end{array}$ & Year & Design & Population & Subjects $n$ & $\begin{array}{l}\text { Outcome } \\
\text { measures }\end{array}$ & $\begin{array}{l}\text { Prevalence of OSA } \\
\text { in given population }\end{array}$ & Results \\
\hline SAMPOL [54] & 2003 & Case-control & $A D$ & $\begin{array}{l}19, \text { plus } 19 \\
\text { controls }\end{array}$ & $\begin{array}{l}A H I \text { in patients } \\
\quad \text { with } A D\end{array}$ & $\begin{array}{c}68 \%(\mathrm{AHI} \\
\left.>5 \text { events } \cdot \mathrm{h}^{-1}\right)\end{array}$ & $\begin{array}{l}A D \text { is associated with a higher } \\
\mathrm{AHI}\end{array}$ \\
\hline MASON [59] & 2010 & Cross-sectional & AAA & 127 & $\begin{array}{l}\text { AAA prevalence } \\
\text { and progession } \\
\text { rate }\end{array}$ & $\begin{array}{c}41.5 \%(\mathrm{AHI} \\
\left.>10 \text { events } \cdot \mathrm{h}^{-1}\right)\end{array}$ & $\begin{array}{l}\text { OSA is highly prevalent in AAA; } \\
\text { severe OSA is associated with a } \\
\text { faster AAA expansion }\end{array}$ \\
\hline HatA [58] & 2011 & Cross-sectional & $A D$ & 139 & $\begin{array}{l}\text { Sleep apnoea } \\
\text { syndrome }\end{array}$ & $\begin{array}{c}\quad 61.4 \%(\mathrm{AHI} \\
\left.>5 \text { events } \cdot \mathrm{h}^{-1}\right)\end{array}$ & $\begin{array}{c}\text { Sleep apnoea syndrome, } \\
\text { insomnia and sleep deprivation } \\
\text { are highly prevalent in patients } \\
\text { with AD aged }<65 \text { years }\end{array}$ \\
\hline YANAGI [57] & 2013 & Cross-sectional & $A D$ & 95 & $\begin{array}{c}\text { Prevalence of } \\
\text { OSA }\end{array}$ & $\begin{array}{l}12.6 \% \text { (clinical } \\
\text { suspicion and } \mathrm{AHI} \\
\geqslant 5 \text { events } \cdot \mathrm{h}^{-1} \text { ) }\end{array}$ & $\begin{array}{c}\text { Patients who have AD with OSA } \\
\text { are characterised by being tall, } \\
\text { fat and relatively young men } \\
\text { with hypertension }\end{array}$ \\
\hline BIANCHI [60] & 2014 & Cross-sectional & AAA & 302 & $\begin{array}{l}\text { Risk of OSA in } \\
\text { elderly AAA } \\
\text { patients }\end{array}$ & $60.6 \%(B Q)$ & $\begin{array}{l}\text { Elderly AAA patients are at high } \\
\text { risk for cardiometabolic disease } \\
\text { and OSA according to the } B Q\end{array}$ \\
\hline ZhANG [56] & 2014 & Case-control & AD (type B) & $\begin{array}{l}82, \text { plus } \\
116 \\
\text { controls }\end{array}$ & $\begin{array}{c}\text { Prevalence of } \\
\text { OSA }\end{array}$ & $\begin{array}{c} \\
81.7 \%(\mathrm{AHI} \\
\left.\geqslant 5 \text { events } \cdot \mathrm{h}^{-1}\right)\end{array}$ & $\begin{array}{c}\text { OSA is highly prevalent and } \\
\text { independently associated with } \\
\text { AD (type B) }\end{array}$ \\
\hline
\end{tabular}

AD: aortic dissection; AHI: apnoea-hypopnoea index; AAA: abdominal aortic aneurysm; ODI: oxygen desaturation index; IHR: intermittent hypoxia and re-oxygenation; TAA: thoracic aortic aneurysm; BQ: Berlin Questionnaire.

TABLE 3 Experimental studies on the association between obstructive sleep apnoea (OSA) and aortic disease in healthy volunteers

\begin{tabular}{lll}
$\begin{array}{l}\text { First author } \\
\text { [ref.] }\end{array}$ & Year Subjects $n$ & Outcome measures \\
\hline
\end{tabular}

\begin{tabular}{|c|c|c|c|c|}
\hline STÖWHAS [62] & 2011 & 20 & $\begin{array}{c}\text { Thoracic aortic diameter during simulated OSA } \\
\text { measured via ultrasonography }\end{array}$ & $\begin{array}{l}\text { Simulated hypopnoea increases proximal aortic } \\
\text { diameter by }+6.5 \% \text { (SE } 3.03, p=0.007 \text { ) and reduces } \\
\text { blood pressure in the aortic root by }-10.5 \mathrm{mmHg} \\
\text { (SE } 2.2 \mathrm{mmHg}, \mathrm{p}<0.001 \text { ); blood pressure also } \\
\text { increased significantly on release of simulated OSA }\end{array}$ \\
\hline Clarenbach [63] & 2013 & 10 & $\begin{array}{l}\text { Thoracic aortic transmural pressure laortic } \\
\text { mean blood pressure minus oesophageal } \\
\text { pressurel during simulated OSA }\end{array}$ & $\begin{array}{l}\text { Simulated obstructive apnoea induced median } \\
+16.3 \mathrm{mmHg}(\text { IQR } 12.8-19.4 \mathrm{mmHg} ; \mathrm{p}=0.02) \text { extra } \\
\text { aortic dilatory force because intra-aortic pressures } \\
\text { fall less than oesophageal pressures }\end{array}$ \\
\hline RAMMOHAN [64] & 2014 & 6 & $\begin{array}{c}\text { Thoracic aortic area during simulated OSA } \\
\text { measured via ultrasonography }\end{array}$ & $\begin{array}{c}\text { Simulated obstructive apnoea increases aortic area } \\
\text { by a mean } \pm \text { SD of }+0.43 \pm 0.08 \mathrm{~cm}^{2}(p=0.002)\end{array}$ \\
\hline
\end{tabular}


Current limitations of published studies

The aforementioned observational studies demonstrate a great deal of heterogeneity in study design approaches and in the populations studied. These variations include, for example, the facts that the treatment status of OSA was not taken into account [46], common diagnostic criteria have not been consistently applied $[45,47,51]$ and some studies lacked a control group $[46,58,60]$. In studies assessing the thoracic aorta there is also a high between-study variation in methodological aspects, as studies do not use consistent anatomic landmarks [41, 44-47, 49-51]. When considering conflicting results among thoracic and abdominal diameters measured at different anatomic landmarks and the fact that, even in a single study, aortic diameters at different landmarks were distinctly affected by OSA, one may hypothesise that the aetiological significance of OSA may vary along the aorta [53]. Furthermore, specific OSA severity groups are often not reported and are most likely underpowered [41, 44-46, 50, 51, 61]. The latter represents a limitation, as the results of several studies suggest that the more severe end of the OSA spectrum (AHI $\geqslant 30$ events. $h^{-1}$ ) accounts for the impact of OSA on aortic disease $[47,49,54,55,59,61]$.

A significant proportion of studies in this review were submitted in the form of short notes [51, 58] or correspondence letters [45, 50], or their main outcome was something other than aortic diameter [44]. Therefore, they were originally designed with an objective other than investigating the association between OSA and aortic dilation. The possibility exists that the initial finding of a statistically significant association between OSA and aortic diameter evoked authors to selectively report their (mostly positive $[45,50,51,58])$ data, thus creating a publication bias. Finally, studies on the prevalence of aortic disease in OSA patients are lacking. This makes it difficult to assess the actual overall impact of OSA on aortic disease.

Besides Marfan's syndrome, there are other heritable connective tissue disorders (e.g. Ehlers-Danlos syndrome and Loeys-Dietz syndrome) that are associated with aortic complications [66-69]. However, studies on the prevalence of OSA and the impact of OSA on aortic disease in these conditions are lacking. Nevertheless, it is important to keep in mind that patients with connective tissue disorders are prone to developing OSA, in general due to alterations affecting the pharyngeal soft tissue. However, because of the different pathophysiology these patients may not be representative for the usual OSA patient group.

\section{Potential mechanisms for the association between OSA and aortic disease}

The underlying mechanism(s) through which OSA may promote aortic disease and thus be a risk factor for aneurysm development are not fully understood. Studies investigating the impact of OSA on aortic disease have discussed several pathomechanisms (for thoracic aorta, see figure 2), including intrathoracic pressure changes leading to shear stress on artery walls $[41,43,49,51,54,55,62,63]$, intermittent hypoxia leading to oxidative stress and sympathetic stimulation $[49,50,55]$, and arousal-induced sympathetic activation with subsequent repetitive blood pressure surges $[45,47,50,54,55,59,61]$. These mechanisms are discussed in the following section.

\section{Intrathoracic pressure changes}

Repetitive apnoeic episodes in OSA result in inspiratory effort against the occluded airway, producing negative intrathoracic pressure swings. These forces support (already elevated) blood pressure to stretch the aortic walls where blood pressure surges are highest and lead to pathological shear stress. It is known that systolic blood pressure hastens the fragmentation of fibrin and collagen deposition with secondary stiffening of the aortic wall [47]. Additional physical dilation or shear stress itself might be another important factor for developing atherosclerosis [70].

In animals, increased aortic diameters during obstructive apnoeas have been observed [71, 72]. In humans, the negative end-apnoeic pressures were quantified in one in vivo study $(\mathrm{n}=74)$, with a mean $\pm \mathrm{SD}$ of $-53.6 \pm 2.9 \mathrm{cmH}_{2} \mathrm{O}$ and peak pressure of $-147.4 \mathrm{cmH}_{2} \mathrm{O}$ [73]. Compared with physiological inspiration pressure of around -5 to $-8 \mathrm{cmH}_{2} \mathrm{O}$ in healthy subjects [74] or nocturnal systolic blood pressure of around $160 \mathrm{cmH}_{2} \mathrm{O}$ (equal to $120 \mathrm{mmHg}$, which is considered the upper limit for normal nocturnal blood pressure [75]), apnoeic episodes in OSA can involve a substantial amount of energy. One study found that the extent of extra aortic dilatory force originating from simulated obstructive apnoea was $16.3 \mathrm{mmHg}$ (interquartile range $12.8-19.4 \mathrm{mmHg} ; \mathrm{p}=0.02$ ) [63]. Therefore, a significant proportion of negative pressure is forwarded to the walls of the aorta and OSA may mechanically promote dilation. Negative intrathoracic pressure changes are also thought to contribute to aortic dilation in patients with Marfan's syndrome $[41,43]$. Due to the fact that OSA subgroups are evenly distributed among AD, TAA and AAA patients, mechanisms other than solely thoracic ones must play a role in the pathogenesis of aortic disease in general [61]. 
FIGURE 2 Proposed mechanisms underpinning the association between obstructive sleep apnoea and thoracic aortic disease.

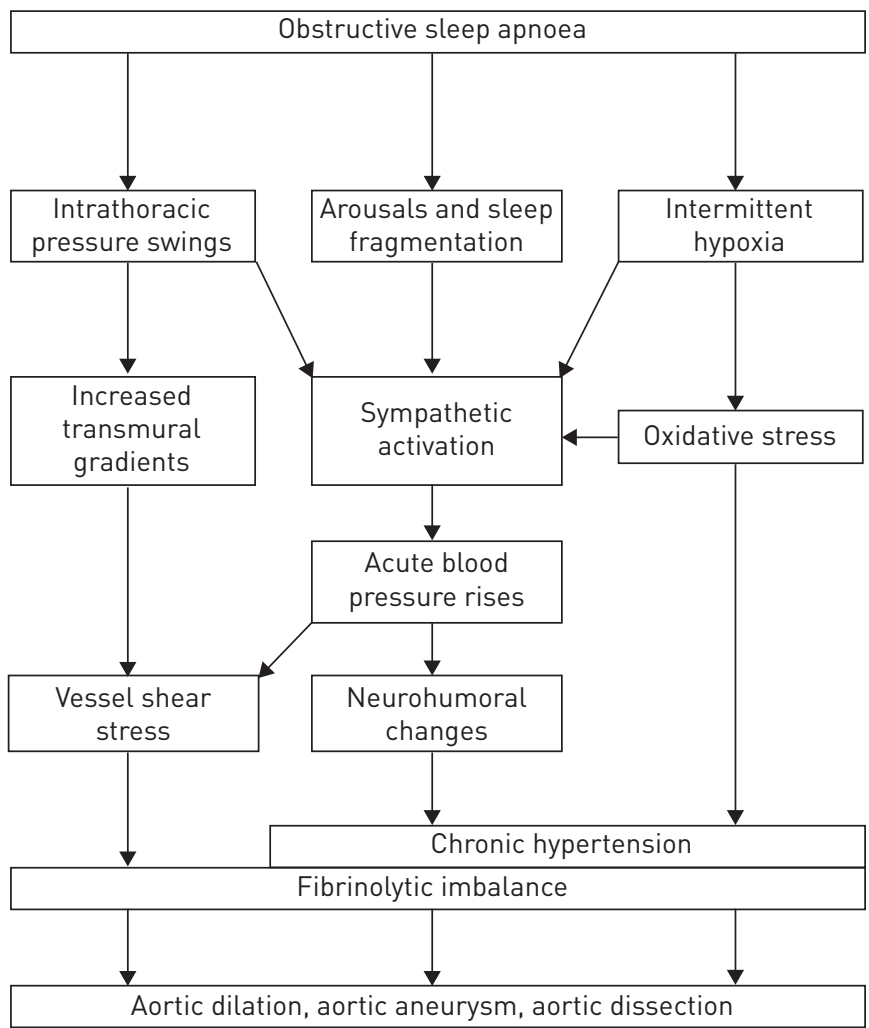

Arousal-induced sympathetic activation

In OSA, cessation of the airway flow can last up to $1 \mathrm{~min}$. As a consequence, blood oxygen levels decrease and carbon dioxide levels rise. Each apnoeic event is accompanied by an arousal, which leads to large transient increases in blood pressure $(\sim 80 \mathrm{mmHg})$ despite a fall in cardiac output [76]. In OSA these events are caused by sympathetic vasoconstriction [77] and their consequences include catecholamine release [77], endothelial dysfunction [78] and probably aortic disease itself [43, 46, 47, 49, 51]. Although these pathophysiological haemodynamic and neurohumoral changes occur during sleep, their consequences persist for $24 \mathrm{~h}$ [79]. Hypertension is present in $72 \%$ of $\mathrm{AD}$ [26], 60\% of TAA [23] and $\sim 75 \%$ of AAA [59] patients and there is consensus that the main identified risk factor for aortic dilation is systemic hypertension. Previous studies have shown that increased sympathetic drive in OSA can accelerate atherosclerosis and lead to impairment of the aortic elasticity property in the setting of hypertension [80, 81]. It has also been proposed that increased afterload from OSA-driven systemic hypertension determines aortic diameter [47]. Therefore, acute as well as chronic hypertension represents a crucial and clinically important pathway in the consequences of OSA and pathogenesis of aortic disease.

\section{Intermittent hypoxia}

The previously described short-term increases in arterial blood pressure at the end of an obstructive apnoea episode are mediated by sympathetic activity [82]. These blood pressure surges seem to be blunted during oxygen administration in OSA patients, suggesting that arterial hypoxaemia influences the autonomous nervous system in OSA patients via chemoreceptors [82]. Hypoxia is associated with the production of reactive oxygen species, which augment pro-inflammatory cytokines and enhance the production of adhesion molecules in endothelial cells/leukocytes, and promote atherosclerosis [83]. In a rodent model, intermittent hypoxia increased chemoreflex and depressed baroreflex, resulting in sympathoadrenal hyperactivity [84]. In humans, intermittent hypoxia due to OSA has been proposed to induce hypertension via increased release of vasoactive substances [85] and peripheral chemoreceptors [86]. In OSA patients, the severity of OSA is independently associated with oxidative stress caused by apnoeic events [87]. In several studies, the decrease of arterial oxygen saturation measured by pulse oximetry was correlated with the degree of aortic stiffness, a well-established disease parameter [44, 49]. Hypoxia has also been associated with increased carotid [88] and aortic root diameters [51]. Hence, hypoxia represents a potential contributor to systemic hypertension and atherosclerosis, both of which are mechanisms involved in the development of aortic disease. 
Inflammatory process

In contrast to the aforementioned mechanisms, the inflammation mechanism is largely theoretical. Although some studies included in this review have considered inflammation as a potential mechanism, none specifically investigated its impact $[44,53,55,56,59,61]$.

It has been shown that the formation of some aortic aneurysms is a progressive inflammatory process [24, 89]. Inflammation is thought to orchestrate the various pathophysiological processes that lead to aortic aneurysms in the first place [90]. About 5\% of TAA [89] and AAA [24] are inflammatory aneurysms (not to be confused with infected aortic aneurysms), which are characterised by marked aortic wall thickening with increased vascularity. They are considered an extreme form of aneurysm, where inflammation itself represents the dominant factor [24]. Anti-inflammatory drugs such as aspirin have shown promising effects in reducing aortic wall inflammation and growth rate in patients with AAA [91]. Because OSA has been suggested to have a systemic pro-inflammatory effect [92] and directly affects the vascular endothelium by promoting local inflammation [93], it is possible that OSA potentiates aortic dilation via this mechanism.

\section{Interactions between mechanisms}

The mechanisms described often act via the sympathetic nervous system and acute or chronic elevated blood pressure represents one common pathway. Blood pressure constantly oscillates (systole, diastole) as part of normal heart physiology but additional rises with OSA can cause chronic damage. It is entirely possible for mechanisms to be coupled and act in parallel. For example, negative intrathoracic pressure swings and transient blood pressure surges might synergistically encourage dilation of the aorta (already weakened by factors such as atherosclerosis) several hundred times at night. However, it is important to keep in mind that there are very few observations and high inter-individual variability of both parameters; hence, only a limited group of OSA patients might actually be affected via these mechanisms. Although some clinical studies suggest a common adverse effect of OSA on TAA, AAA and AD [61], one must consider the possibility that the pathophysiology of each disease may differ. This view is encouraged by the fact that TAA, AAA and AD do not share the same risk factors [94]. For example, atherosclerosis is positively associated with AAA [95] while evidence suggests it is negatively associated with TAA [96]. It is crucial to have a detailed knowledge of the underlying pathophysiology so that future treatments will target the right mechanism(s).

\section{Implications for further research}

Role of treatment

The present standard treatment for OSA is CPAP. It has been demonstrated that sustained and effective nocturnal CPAP treatment can lower ambulatory blood pressure, eliminate the ensuing acute haemodynamic changes during sleep and improve early signs of atherosclerosis [15, 81, 97, 98]. Determining whether aortic disease is caused by the acute effects of apnoeic episodes or the chronic structural and autonomic changes resulting from untreated OSA is likely to result in important implications for therapy [99]. In the case of acute events, CPAP treatment of OSA can abolish the acute blood pressure surges and/or intrathoracic pressure swings and lower diurnal blood pressure. However, effective CPAP treatment presents a considerable clinical challenge, as only about $30-60 \%$ of patients are adherent to CPAP [100]. Conversely, if long-term autonomic effects of OSA cause major aortic damage, there may be effective alternative therapy approaches to avoid these pathomechanisms, including (in theory) pharmacological modalities and renal sympathetic denervation [99].

In light of the proposed association between OSA and aortic disease, it is reasonable to hypothesise that CPAP might also attenuate (but not reverse) aortic root dilation in Marfan's syndrome [101, 102] and aortic aneurysm expansion rate [59]. Further steps include determining the value of CPAP treatment in the primary and secondary prevention of aortic disease in OSA patients and assessing the benefits of OSA screening in patients with aortic disease.

\section{Threshold effect}

The current literature suggests that the adverse impact of OSA on aortic dilation [49], TAA [61], AAA [53, $59,61]$ and $\mathrm{AD}[54,55,61]$ only occurs above a certain severity level between moderate and severe OSA. It appears likely that there is not a straightforward linear dose-response relationship between OSA severity and aortic disease but perhaps a threshold effect $[47,54,59]$. Depending on the proposed underlying mechanisms, other measures of disease severity, such as number of apnoeas per hour, pulse transit time [103] or arousal index, may be alternative or more accurate approaches for identifying patients at risk for aortic dilation. This needs to be further investigated. 


\section{Future research}

Future studies need to control for additional risk factors (primarily for hypertension) and effect modifiers. Although observational studies have, at least in part, reported an association between OSA and aortic disease, it is too early to presume a causal relationship due to the lack of randomised controlled trials. However, identifying a causal role of OSA on aortic disease is very difficult to establish, since aortic disease is a chronic condition and usually has a very long latent period before the first (and potentially fatal) symptoms emerge. This is aggravated by the fact that the genesis of aortic aneurysms and AD are believed to have multifactorial overlapping risk factors and many of them are overlapping with those of OSA. Finally, a randomised controlled trial faces the ethical issue of treating a high number of OSA patients with sham CPAP for several years.

Based on the current literature, the main points for future research are as follows. 1) The sample size of studies in this field is relatively low. High quality studies with larger sample sizes, especially in the thus far underrepresented severe OSA group (AHI $>30$ events $\cdot h^{-1}$ ), are needed to study a potential minimum threshold level for increased risk of aortic disease. 2) Prevalence studies of aortic disease in OSA patients are lacking. These numbers are needed to further quantify the association between OSA and aortic disease. 3) A further investigation of primary and secondary preventative measures of aortic disease in OSA is required. Randomised controlled trials are needed to potentially assess a causal relationship. 4) Longitudinal studies of disease parameters and clinical outcomes (e.g. aortic events in OSA) are needed in order to assess the potential long-term impact of OSA on aortic disease. 5) Prevalence studies on OSA in conditions associated with aortic problems (e.g. connective tissue diseases other than Marfan's syndrome) are needed in order to determine the impact of OSA on potentially vulnerable individuals. 6) A meta-analysis of individual patient data from relevant studies is warranted to quantify the association between thoracic aortic root size and the severity of OSA more precisely. 7) A common set of definitions and diagnostic methods for OSA are highly recommended to decrease clinical heterogeneity of studies and allow for a systematic comparison.

\section{Conclusions}

Several studies have shown an association between OSA and aortic dilation. OSA has been found to be highly prevalent in patients with aortic aneurysms and severe OSA seems to be associated with more rapid progression of AAA. Possible mechanisms that might promote aortic dilation include intrathoracic pressure changes, repetitive blood pressure surges and chronic hypertension, as well as atherosclerosis induced by intermittent hypoxia. However, there is a need for well-controlled prospective studies in order to establish a causal relationship between OSA and aortic dilation.

\section{References}

1 Young T, Palta M, Dempsey J, et al. The occurrence of sleep-disordered breathing among middle-aged adults. N Engl J Med 1993; 328: 1230-1235.

2 Young T, Hutton R, Finn L, et al. The gender bias in sleep apnea diagnosis. Are women missed because they have different symptoms? Arch Intern Med 1996; 156: 2445-2451.

3 Peppard PE, Young T, Barnet JH, et al. Increased prevalence of sleep-disordered breathing in adults. Am J Epidemiol 2013; 177: 1006-1014.

4 Heinzer R, Vat S, Marques-Vidal P, et al. Prevalence of sleep-disordered breathing in the general population: the HypnoLaus study. Lancet Respir Med 2015; 3: 310-318.

5 Gottlieb DJ, Yenokyan G, Newman AB, et al. Prospective study of obstructive sleep apnea and incident coronary heart disease and heart failure: the sleep heart health study. Circulation 2010; 122: 352-360.

6 Marin JM, Carrizo SJ, Vicente E, et al. Long-term cardiovascular outcomes in men with obstructive sleep apnoea-hypopnoea with or without treatment with continuous positive airway pressure: an observational study. Lancet 2005; 365: 1046-1053.

7 Redline S, Yenokyan G, Gottlieb DJ, et al. Obstructive sleep apnea-hypopnea and incident stroke: the sleep heart health study. Am J Respir Crit Care Med 2010; 182: 269-277.

8 Punjabi NM, Caffo BS, Goodwin JL, et al. Sleep-disordered breathing and mortality: a prospective cohort study. PLoS Med 2009; 6: e1000132.

9 Haentjens P, Van Meerhaeghe A, Moscariello A, et al. The impact of continuous positive airway pressure on blood pressure in patients with obstructive sleep apnea syndrome: evidence from a meta-analysis of placebo-controlled randomized trials. Arch Intern Med 2007; 167: 757-764.

10 Kohler M, Stradling JR. Mechanisms of vascular damage in obstructive sleep apnea. Nat Rev Cardiol 2010; 7: 677-685.

11 Peppard PE, Young T, Palta M, et al. Prospective study of the association between sleep-disordered breathing and hypertension. N Engl J Med 2000; 342: 1378-1384.

12 Nieto FJ, Young TB, Lind BK, et al. Association of sleep-disordered breathing, sleep apnea, and hypertension in a large community-based study. Sleep Heart Health Study. JAMA 2000; 283: 1829-1836.

13 Jenkinson C, Davies RJ, Mullins R, et al. Comparison of therapeutic and subtherapeutic nasal continuous positive airway pressure for obstructive sleep apnoea: a randomised prospective parallel trial. Lancet 1999; 353: 2100-2105.

14 Avlonitou E, Kapsimalis F, Varouchakis G, et al. Adherence to CPAP therapy improves quality of life and reduces symptoms among obstructive sleep apnea syndrome patients. Sleep Breath 2012; 16: 563-569. 

subtherapeutic nasal continuous positive airway pressure for obstructive sleep apnoea: a randomised parallel trial. Lancet 2002; 359: 204-210.

16 Pedrosa RP, Drager LF, de Paula LK, et al. Effects of OSA treatment on BP in patients with resistant hypertension: a randomized trial. Chest 2013; 144: 1487-1494.

17 Johnston KW, Rutherford RB, Tilson MD, et al. Suggested standards for reporting on arterial aneurysms. Subcommittee on Reporting Standards for Arterial Aneurysms, Ad Hoc Committee on Reporting Standards, Society for Vascular Surgery and North American Chapter, International Society for Cardiovascular Surgery. J Vasc Surg 1991; 13: 452-458.

18 Kälsch H, Lehmann N, Möhlenkamp S, et al. Body-surface adjusted aortic reference diameters for improved identification of patients with thoracic aortic aneurysms: results from the population-based Heinz Nixdorf Recall study. Int J Cardiol 2013; 163: 72-78.

19 Itani Y, Watanabe S, Masuda Y, et al. Measurement of aortic diameters and detection of asymptomatic aortic aneurysms in a mass screening program using a mobile helical computed tomography unit. Heart Vessels 2002; 16: $42-45$.

20 Lederle FA, Johnson GR, Wilson SE, et al. The aneurysm detection and management study screening program: validation cohort and final results. Aneurysm Detection and Management Veterans Affairs Cooperative Study Investigators. Arch Intern Med 2000; 160: 1425-1430.

21 National Center for Injury Prevention and Control. WISQARS Leading Causes of Death Reports, $1999-2007$. http://webappa.cdc.gov/sasweb/ncipc/leadcaus10.html Date last updated: June 1, 2010. Date last accessed: April $21,2015$.

Isselbacher EM. Thoracic and abdominal aortic aneurysms. Circulation 2005; 111: 816-828.

1982; 92: 1103-1108.

Rasmussen TE, Hallett JW Jr. Inflammatory aortic aneurysms. A clinical review with new perspectives in pathogenesis. Ann Surg 1997; 225: 155-164.

Reed D, Reed C, Stemmermann G, et al. Are aortic aneurysms caused by atherosclerosis? Circulation 1992; 85: 205-211.

26 Hagan PG, Nienaber CA, Isselbacher EM, et al. The International Registry of Acute Aortic Dissection (IRAD): new insights into an old disease. JAMA 2000; 283: 897-903.

27 Kario K. Obstructive sleep apnea syndrome and hypertension: ambulatory blood pressure. Hypertens Res 2009; 32: 428-432.

28 Young T, Palta M, Dempsey J, et al. Burden of sleep apnea: rationale, design, and major findings of the Wisconsin Sleep Cohort study. WMJ 2009; 108: 246-249.

29 Vasan RS, Larson MG, Levy D. Determinants of echocardiographic aortic root size. The Framingham Heart Study. Circulation 1995; 91: 734-740.

30 Lederle FA, Johnson GR, Wilson SE, et al. Prevalence and associations of abdominal aortic aneurysm detected through screening. Aneurysm Detection and Management (ADAM) Veterans Affairs Cooperative Study Group. Ann Intern Med 1997; 126: 441-449.

31 Stradling JR, Davies RJ. Sleep. 1: Obstructive sleep apnoea/hypopnoea syndrome: definitions, epidemiology, and natural history. Thorax 2004; 59: 73-78.

32 Young T, Skatrud J, Peppard PE. Risk factors for obstructive sleep apnea in adults. JAMA 2004; $291: 2013-2016$.

33 Quintana-Gallego E, Carmona-Bernal C, Capote F, et al. Gender differences in obstructive sleep apnea syndrome: a clinical study of 1166 patients. Respir Med 2004; 98: 984-989.

34 Cistulli PA, Gotsopoulos H, Sullivan CE. Relationship between craniofacial abnormalities and sleep-disordered breathing in Marfan's syndrome. Chest 2001; 120: 1455-1460.

35 Cistulli PA, Sullivan CE. Influence of maxillary morphology on nasal airway resistance in Marfan's syndrome. Acta Otolaryngol 2000; 120: 410-413.

36 Cistulli PA, Richards GN, Palmisano RG, et al. Influence of maxillary constriction on nasal resistance and sleep apnea severity in patients with Marfan's syndrome. Chest 1996; 110: 1184-1188.

37 Cistulli PA, Sullivan CE. Sleep apnea in Marfan's syndrome. Increased upper airway collapsibility during sleep. Chest 1995; 108: 631-635.

38 Cañadas V, Vilacosta I, Bruna I, et al. Marfan syndrome. Part 2: treatment and management of patients. Nat Rev Cardiol 2010; 7: 266-276.

39 Murdoch JL, Walker BA, Halpern BL, et al. Life expectancy and causes of death in the Marfan syndrome. N Engl J Med 1972; 286: 804-808.

40 Cistulli PA, Sullivan CE. Sleep-disordered breathing in Marfan's syndrome. Am Rev Respir Dis 1993; 147: 645-648.

41 Kohler M, Blair E, Risby P, et al. The prevalence of obstructive sleep apnoea and its association with aortic dilatation in Marfan's syndrome. Thorax 2009; 64: 162-166.

42 Rybczynski M, Koschyk D, Karmeier A, et al. Frequency of sleep apnea in adults with the Marfan syndrome. Am J Cardiol 2010; 105: 1836-1841.

43 Kohler M, Pitcher A, Blair E, et al. The impact of obstructive sleep apnea on aortic disease in Marfan's syndrome. Respiration 2013; 86: 39-44.

44 Tanriverdi H, Evrengul H, Kara CO, et al. Aortic stiffness, flow-mediated dilatation and carotid intima-media thickness in obstructive sleep apnea: non-invasive indicators of atherosclerosis. Respiration 2006; 73: 741-750.

45 Serizawa N, Yumino D, Takagi A, et al. Obstructive sleep apnea is associated with greater thoracic aortic size. J Am Coll Cardiol 2008; 52: 885-886.

46 Meuleman C, Boccara F, Nguyen XL, et al. Is the aortic root dilated in obstructive sleep apnoea syndrome? Arch Cardiovasc Dis 2008; 101: 391-397.

47 Lee LC, Torres MC, Khoo SM, et al. The relative impact of obstructive sleep apnea and hypertension on the structural and functional changes of the thoracic aorta. Sleep 2010; 33: 1173-1176.

48 Pedrosa RP, Drager LF, Genta PR, et al. Obstructive sleep apnea is common and independently associated with atrial fibrillation in patients with hypertrophic cardiomyopathy. Chest 2010; 137: 1078-1084. 

function and aortic root parameters in newly diagnosed, untreated patients: a prospective study. J Int Med Res 2011; 39: 2228-2238.

50 Achour EC, Roche F, Romeyer-Bouchard C, et al. Aortic root size and sleep apnea in elderly: a cohort study. Int J Cardiol 2011; 151: 101-102.

51 Baguet JP, Minville C, Tamisier R, et al. Increased aortic root size is associated with nocturnal hypoxia and diastolic blood pressure in obstructive sleep apnea. Sleep 2011; 34: 1605-1607.

52 Chen YL, Su MC, Liu WH, et al. Influence and predicting variables of obstructive sleep apnea on cardiac function and remodeling in patients without congestive heart failure. J Clin Sleep Med 2014; 10: 57-64.

53 Tachikawa R, Hamada S, Azuma M, et al. Impact of obstructive sleep apnea on abdominal aortic diameters. Am J Cardiol 2014; 114: 618-623.

54 Sampol G, Romero O, Salas A, et al. Obstructive sleep apnea and thoracic aorta dissection. Am J Respir Crit Care Med 2003; 168: 1528-1531.

55 Naito R, Sakakura K, Kasai T, et al. Aortic dissection is associated with intermittent hypoxia and re-oxygenation. Heart Vessels 2012; 27: 265-270.

56 Zhang X, Zhang T, Zhang X, et al. Obstructive sleep apnea syndrome: a risk factor for Stanford's type B aortic dissection. Ann Vasc Surg 2014; 28: 1901-1908.

57 Yanagi H, Imoto K, Suzuki S, et al. Acute aortic dissection associated with sleep apnea syndrome. Ann Thorac Cardiovasc Surg 2013; 19: 456-460.

58 Hata M, Yoshitake I, Wakui S, et al. Sleep disorders and aortic dissection in a working population. Surg Today 2012; 42: 403-405.

59 Mason RH, Ruegg G, Perkins J, et al. Obstructive sleep apnea in patients with abdominal aortic aneurysms: highly prevalent and associated with aneurysm expansion. Am J Respir Crit Care Med 2011; 183: 668-674.

60 Bianchi VE, Herbert WG, Myers J, et al. Relationship of obstructive sleep apnea and cardiometabolic risk factors in elderly patients with abdominal aortic aneurysm. Sleep Breath 2015; 19: 593-598.

61 Saruhara H, Takata Y, Usui Y, et al. Obstructive sleep apnea as a potential risk factor for aortic disease. Heart Vessels 2012; 27: 166-173.

62 Stöwhas AC, Namdar M, Biaggi P, et al. The effect of simulated obstructive apnea and hypopnea on aortic diameter and BP. Chest 2011; 140: 675-680.

63 Clarenbach CF, Camen G, Sievi NA, et al. Effect of simulated obstructive hypopnea and apnea on thoracic aortic wall transmural pressures. J Appl Physiol 2013; 115: 613-617.

64 Rammohan HR, Murthy K, Pressman GS. Effects of the Mueller Maneuver on aortic area. Int J Cardiol 2014; 173: $128-129$.

65 Hanly PJ, George CF, Millar TW, et al. Heart rate response to breath-hold, valsalva and Mueller maneuvers in obstructive sleep apnea. Chest 1989; 95: 735-739.

66 Pepin M, Schwarze U, Superti-Furga A, et al. Clinical and genetic features of Ehlers-Danlos syndrome type IV, the vascular type. N Engl J Med 2000; 342: 673-680.

67 Wenstrup RJ, Meyer RA, Lyle JS, et al. Prevalence of aortic root dilation in the Ehlers-Danlos syndrome. Genet Med 2002; 4: 112-117.

68 Loeys BL, Chen J, Neptune ER, et al. A syndrome of altered cardiovascular, craniofacial, neurocognitive and skeletal development caused by mutations in TGFBR1 or TGFBR2. Nat Genet 2005; 37: 275-281.

69 Loeys BL, Schwarze U, Holm T, et al. Aneurysm syndromes caused by mutations in the TGF- $\beta$ receptor. $N$ Engl $J$ Med 2006; 355: 788-798.

70 Lovett JK, Rothwell PM. Site of carotid plaque ulceration in relation to direction of blood flow: an angiographic and pathological study. Cerebrovasc Dis 2003; 16: 369-375.

71 Peters J, Kindred MK, Robotham JL. Transient analysis of cardiopulmonary interactions. I. Diastolic events. J Appl Physiol 1988; 64: 1506-1517.

72 Peters J, Kindred MK, Robotham JL. Transient analysis of cardiopulmonary interactions. II. Systolic events. J Appl Physiol 1988; 64: 1518-1526.

73 Suzuki M, Ogawa H, Okabe S, et al. Digital recording and analysis of esophageal pressure for patients with obstructive sleep apnea-hypopnea syndrome. Sleep Breath 2005; 9: 64-72.

74 Rhoades RA, Bell DR, eds. Medical Physiology: Principles for Clinical Medicine. 4th Edn. Philadelphia, Lippincott Williams and Wilkins, 2013.

75 Pickering TG, Hall JE, Appel LJ, et al. Recommendations for blood pressure measurement in humans and experimental animals. Part 1: Blood pressure measurement in humans: a statement for professionals from the Subcommittee of Professional and Public Education of the American Heart Association Council on High Blood Pressure Research. Hypertension 2005; 45: 142-161.

76 Garpestad E, Parker JA, Katayama H, et al. Decrease in ventricular stroke volume at apnea termination is independent of oxygen desaturation. J Appl Physiol 1994; 77: 1602-1608.

77 Somers VK, Dyken ME, Clary MP, et al. Sympathetic neural mechanisms in obstructive sleep apnea. J Clin Invest 1995; 96: 1897-1904.

78 Kato M, Roberts-Thomson P, Phillips BG, et al. Impairment of endothelium-dependent vasodilation of resistance vessels in patients with obstructive sleep apnea. Circulation 2000; 102: 2607-2610.

79 Carlson JT, Hedner J, Elam M, et al. Augmented resting sympathetic activity in awake patients with obstructive sleep apnea. Chest 1993; 103: 1763-1768.

80 Tsioufis C, Thomopoulos K, Dimitriadis K, et al. The incremental effect of obstructive sleep apnoea syndrome on arterial stiffness in newly diagnosed essential hypertensive subjects. J Hypertens 2007; 25: 141-146.

81 Drager LF, Bortolotto LA, Figueiredo AC, et al. Effects of continuous positive airway pressure on early signs of atherosclerosis in obstructive sleep apnea. Am J Respir Crit Care Med 2007; 176: 706-712.

82 Leuenberger U, Jacob E, Sweer L, et al. Surges of muscle sympathetic nerve activity during obstructive apnea are linked to hypoxemia. J Appl Physiol 1995; 79: 581-588.

83 Savransky V, Nanayakkara A, Li J, et al. Chronic intermittent hypoxia induces atherosclerosis. Am J Respir Crit Care Med 2007; 175: 1290-1297. 
Dematteis M, Julien C, Guillermet C, et al. Intermittent hypoxia induces early functional cardiovascular remodeling in mice. Am J Respir Crit Care Med 2008; 177: 227-235.

85 Kanagy NL, Walker BR, Nelin LD. Role of endothelin in intermittent hypoxia-induced hypertension. Hypertension 2001; 37: 511-515.

86 Lesske J, Fletcher EC, Bao G, et al. Hypertension caused by chronic intermittent hypoxia - influence of chemoreceptors and sympathetic nervous system. J Hypertens 1997; 15: 1593-1603.

87 Yamauchi M, Nakano H, Maekawa J, et al. Oxidative stress in obstructive sleep apnea. Chest 2005; 127: 1674-1679.

88 Lefebvre B, Pépin JL, Baguet JP, et al. Leukotriene B4: early mediator of atherosclerosis in obstructive sleep apnoea? Eur Respir J 2008; 32: 113-120.

89 Pacini D, Leone O, Turci S, et al. Incidence, etiology, histologic findings, and course of thoracic inflammatory aortopathies. Ann Thorac Surg 2008; 86: 1518-1523.

90 Eagleton MJ. Inflammation in abdominal aortic aneurysms: cellular infiltrate and cytokine profiles. Vascular 2012; 20: 278-283

91 Lindholt JS, Sorensen HT, Michel JB, et al. Low-dose aspirin may prevent growth and later surgical repair of medium-sized abdominal aortic aneurysms. Vasc Endovascular Surg 2008; 42: 329-334.

92 Nadeem R, Molnar J, Madbouly EM, et al. Serum inflammatory markers in obstructive sleep apnea: a meta-analysis. J Clin Sleep Med 2013; 9: 1003-1012.

93 Jelic S, Padeletti M, Kawut SM, et al. Inflammation, oxidative stress, and repair capacity of the vascular endothelium in obstructive sleep apnea. Circulation 2008; 117: 2270-2278.

94 Elefteriades JA, Farkas EA. Thoracic aortic aneurysm clinically pertinent controversies and uncertainties. $J$ Am Coll Cardiol 2010; 55: 841-857.

95 Golledge J, Muller J, Daugherty A, et al. Abdominal aortic aneurysm: pathogenesis and implications for management. Arterioscler Thromb Vasc Biol 2006; 26: 2605-2613.

96 Achneck H, Modi B, Shaw C, et al. Ascending thoracic aneurysms are associated with decreased systemic atherosclerosis. Chest 2005; 128: 1580-1586.

97 Lattimore JD, Celermajer DS, Wilcox I. Obstructive sleep apnea and cardiovascular disease. J Am Coll Cardiol 2003; 41: 1429-1437.

98 Ali NJ, Davies RJ, Fleetham JA, et al. The acute effects of continuous positive airway pressure and oxygen administration on blood pressure during obstructive sleep apnea. Chest 1992; 101: 1526-1532.

99 Gottlieb DJ. Sleep apnea and the risk of atrial fibrillation recurrence: structural or functional effects? J Am Heart Assoc 2014; 3: e000654.

100 Weaver TE, Sawyer AM. Adherence to continuous positive airway pressure treatment for obstructive sleep apnoea: implications for future interventions. Indian J Med Res 2010; 131: 245-258.

101 Cistulli PA, Wilcox I, Jeremy R, et al. Aortic root dilatation in Marfan's syndrome: a contribution from obstructive sleep apnea? Chest 1997; 111: 1763-1766.

102 Verbraecken J, Paelinck BP, Willemen M, et al. Aortic root diameter and nasal intermittent positive airway pressure treatment in Marfan's syndrome. Clin Genet 2003; 63: 131-134.

103 Schwartz DJ. The pulse transit time arousal index in obstructive sleep apnea before and after CPAP. Sleep Med 2005; 6: 199-203. 